El Guiniguada • Revista de investigaciones y experiencias en Ciencias de la Educación

\title{
ENSEÑANZA Y APRENDIZAJE DE LA LITERATURA EN SECUNDARIA: ROMANTICISMO Y REALISMO
}

\author{
TEACHING AND LEARNING LITERATURE \\ IN SECONDARY EDUCATION: ROMANTICISM AND REALISM
}

\author{
Blanca Hernández Quintana \\ Universidad de Las Palmas de Gran Canaria
}

Recibido: 25/01/2015/Aceptado: 14/04/2015

\section{RESUMEN}

En este artículo se presentan varias propuestas didácticas destinadas a trabajar el Romanticismo y el Realismo, dos movimientos literarios incluidos en la programación en el cuarto curso de Educación Secundaria Obligatoria durante la primera evaluación. El objetivo de estas propuestas es convertir al alumnado en parte activa de las clases mediante actividades que favorezcan la creatividad, la reflexión, la comprensión lectora y la interpretación y valoración de la lectura. Del mismo modo, pretendemos que dejen de concebir la literatura como algo aburrido y alejado de los libros, tal y como ellos nos han expresado, y que reflexionen sobre si, tal vez, la concepción del mundo desarrollada en dichos movimientos durante el siglo XIX pueda ayudarles a entender mejor a la sociedad actual.

Palabras clave: práctica docente, aprendizaje literario, Romanticismo y Realismo.

\section{ABSTRACT}

This article discusses several teaching proposals intended to work Romanticism and Realism, two literary movements included in the first term of the anual programming of the fourth grade of the spanish compulsory secondary education. The aim of these proposals is to turn students into an active part of the lessons through activities that encourage creativity, reflection, reading comprehension and interpretation as well as reading assessment. In the same vain, we hope that students 


\section{Blanca Hernández Quintana}

Enseñanza y aprendizaje de la Literatura en Secundaria: Romanticismo y Realismo

stop conceiving literature as something boring and away from books, just as they have expressed to us, and we also encourage them to ponder if, perhaps, the conception of the developed world in such movements during the nineteenth century can help them to understand better today's society.

\section{Keywords: teaching practice, learning literary, Romanticism and Realism.}

Pese a que se han cimentado las bases teóricas necesarias para iniciar una nueva etapa en la enseñanza y aprendizaje de la literatura, lo cierto es que la realidad en las aulas refleja que aún queda mucho por hacer. Esta realidad pone de manifiesto que el alumnado sigue percibiendo esta asignatura como un bloque de contenidos teóricos que memorizar y alejada de los libros y de los textos. Al inicio del curso, pedimos a tres grupos de cuarto de Educación Secundaria Obligatoria que realizaran una lluvia de ideas sobre cómo percibían esta asignatura y sus respuestas fueron: aburrimiento, historia, fechas, autores, memorizar, teoría, rollo, sueño...

Elisa Silió (2013) analiza las reflexiones que, sobre el sistema educativo, realiza Ken Robinson, quien considera que, tal y como está planteado, el sistema educativo reprime los talentos y las habilidades de muchos estudiantes y mata su motivación para aprender. El seguimiento y cumplimiento de los programas y objetivos diseñados para cada curso, encorsetados en un marco excesivamente teórico, anula, en muchas ocasiones, cualquier espacio que promueva la creatividad de los estudiantes, que les haga pensar o enfrentarse a un texto, a un discurso o a una imagen. $\mathrm{Y}$ es, en este espacio, donde concebimos que deberían trabajarse las humanidades y, más concretamente, la literatura.

Durante muchos años, las artes plásticas han sido las encargadas de fomentar la creatividad como respuesta a un sistema educativo diseñado para una sociedad, la de finales del siglo XIX y principios del XX, que tenía que enfrentarse a una realidad unidireccional y lineal. Cada materia era concebida como un compartimento cerrado sin posibilidad de que se estableciera algún tipo de relación entre ellas ni de que se favoreciera la investigación y la experimentación. Estas dos habilidades, la experimentación y la investigación, se desarrollaron, principalmente, en las disciplinas científicas, cuyos resultados han sido la innovación y los avances científicos y tecnológicos de los que hoy disfrutamos. Las humanidades, que no han potenciado lo suficiente estas dos habilidades, parecen no tener cabida en una sociedad que ya no es lineal, sino divergente y que, tal vez, no ha sabido justificar el sentido de su existencia.

No se trata de denostar el marco teórico en aras del monopolio de la creatividad, puesto que ésta se nutre de los conocimientos ya existentes y son la base fundamental del saber. Los estudios teóricos deberían dirigirse hacia la orientación de las 


\section{Blanca Hernández Quintana}

Enseñanza y aprendizaje de la Literatura en Secundaria: Romanticismo y Realismo

nociones imprescindibles sobre las que se asienta cada materia y, de este modo, dotar a los estudiantes de las herramientas necesarias para la adaptación, actualización y uso de dichos conocimientos. Si la educación ha sido concebida para formar y preparar a los estudiantes para saber enfrentarse y ser resolutivos en la sociedad a la que pertenecen, el pragmatismo actual abre una brecha entre la escuela y el mundo real, y es este distanciamiento es el les hace preguntarse constantemente "¿para qué sirve esto?". Seguramente, en la época actual, las humanidades sirven para mucho más que en otras épocas.

El estudio de las humanidades, de la literatura, debería enseñar al alumnado a desarrollar la capacidad crítica, el pensamiento propio, el arte de la retórica y la oratoria, a saber descodificar el discurso, el lenguaje y las imágenes codificadas que imperan hoy, debería enseñarles a apreciar el valor, el poder de las palabras, enseñarles a escuchar, mediante la lectura de libros, otras formas de entender el mundo, de resolver conflictos, de sentir. Como explica Millás, J.J. (2008: 358) el dominio de la palabra es el primer paso, imprescindible, para poder modificar, cambiar aquella parte de la realidad que no va bien, y el primer paso es tomar conciencia de que algo no funciona y para ello hay que aprender a descodificar un discurso que se asume sin ser cuestionado, sin ser pensado. Quizá, como explica este autor, este afán por anular el pensamiento crítico sea el motivo por el que la enseñanza de las humanidades esté tan denostada y cada vez menos presente en los programas escolares.

No entraremos a valorar los conocidos resultados de España en el informe PISA en materia de comprensión lectora, pero, es obvio, que dichos resultados tienen una repercusión inmediata y concreta que se materializan en la vida real. Silió y García (2014) analizan los resultados de un estudio que concluye que los alumnos españoles tienen un "suspenso en la vida real" debido a que no saber aplicar lo aprendido. A esta conclusión se llega al comprobar, mediante una serie de pruebas, que los estudiantes españoles no saben programar un aparato de aire acondicionado, escoger la combinación de metro necesaria para llegar a un punto determinado, interpretar un manual de instrucciones, sacarse un billete de avión..., no son autónomos o resolutivos a la hora de enfrentarse a cuestiones prácticas.

El problema está localizado pero hace falta una solución y ésta pasa, inevitablemente, por una escuela que no se limite a enseñar conocimientos, sino que les enseñe a ser creativos, a buscar soluciones alternativas, a gestionar las emociones y los sentimientos, a entender el mundo en el que viven desde las diferentes perspectivas que ofrece cada asignatura. $\mathrm{Y}$ es desde esta perspectiva desde donde queremos que cobre relevancia los postulados de la didáctica de la literatura.

Teresa Colomer (1996) señala que la literatura contribuye a la formación del individuo tanto en cuanto se concibe como una forma de comunicación social. El discurso elaborado por los escritores a lo largo de los siglos a través de sus libros ha ido conformando el pensamiento cultural de la sociedad que somos hoy y que nos 
define, como sociedad y como individuo. Y ha sido la lectura y la interpretación de sus textos la principal fuente de conocimiento del presente y del pasado. Por eso, Teresa Colomer (1996) sugiere la necesidad de sustituir el término enseñanz̧a de literatura por educación literaria como forma de constatar el cambio de una enseñanza orientada al aprendizaje escolar.

La enseñanza de literatura ha ido cambiando a lo largo de los años y se ha organizado atendiendo a diversas corrientes teóricas y metodológicas, cuyo objetivo es acercarse al estudio y al análisis de cada autor y de la creación literaria desde diferentes perspectivas. Estas perspectivas, a partir de las cuales surgieron otros métodos para el estudio de la literatura, según explica Ballester (1998), se pueden resumir en las siguientes:

- Historicismo: se centra en el estudio de los temas y el estilo de las obras de los textos a lo largo del tiempo.

- Formalismo: rechaza la vertiente historicista y propone el estudio de la forma del texto.

- Estilística: analiza los valores estilísticos utilizados por el escritor motivados, a su vez, por su cultura, las características sociales de su época, su manera de concebir el mundo, etc.

- Sociológica: se agrupan varias tendencias que condicionan el estudio de la creación literaria al contexto en el que ha surgido.

- Estructuralismo: método que decide analizar el discurso a partir de su estructura funcional sin que el autor importe tanto para su comprensión.

- Estética de la recepción: método que abre la puerta al desarrollo de la competencia literaria y se centra en la figura del lector y en su interpretación de los textos.

En la práctica, la enseñanza de la literatura en las aulas de Secundaria se basa, principalmente, en la explicación de los movimientos literarios, delimitados cronológicamente por siglos, en el estudio de los acontecimientos históricos y sociales acontecidos durante cada periodo y en el análisis de la vida y obras de cada autor atendiendo a los temas y al estilo empleados, con la variante del comentario de textos que sintetiza cada uno de estos apartados. Cada corriente teórica ha aportado un aspecto diferente desde el que analizar la obra literaria y la ha ido enriqueciendo. Pero, se trata de fundamentos teóricos, quizá, más propios del saber académico y universitario que, con mayor o menor éxito, se han colado en las aulas de literatura de la enseñanza básica. La sistematización histórica ha sido un recurso muy útil, una herramienta pedagógica que ayuda a contextualizar a un autor o a los movimientos literarios dentro de una serie de cajones con una etiqueta en los que se guardan las características que lo identifican. Sin desdeñar el necesario conocimiento de los contenidos históricos 
y teóricos, claves para entender por qué se escribió con un estilo concreto o por qué se trató un tema determinado, no podemos hacer que ellos protagonicen el programa de la asignatura. Definidos los fundamentos teóricos básicos, es el texto y el lector quienes toman la palabra.

Poco espacio ha quedado en las aulas para lo realmente importante: la lectura de fragmentos, poemas y libros. Poco espacio ha quedado para escuchar esa cadena de diálogos que los libros han ido estableciendo entre ellos a lo largo de los siglos. Un diálogo elaborado a partir de las conversaciones de los textos anteriores a los que se suma, en el siguiente, una nueva forma de ver el mundo y una forma diferente de contarlo.

Como explica Bordons y Díaz-Plaja (2006), la llegada de los enfoques centrados en la obra recuperó la lectura literaria, aunque concentrada en un análisis desde una perspectiva estructural o retórica que resultó agotador para los estudiantes. Habría que esperar a la llegada de la teoría de la recepción para que el lector se hiciera lector, y su punto de vista empezara a tener voz. Para conseguirlo, los docentes tienen la labor de demostrar al alumnado que los libros no son objetos muertos y cerrados, sino que están vivos, que se puede establecer un diálogo con ellos y cuestionar o adaptar su contenido. La enseñanza intenta focalizar su atención en la relación entre texto y lector y, como paso previo, Mendoza Fillola (2004) señala la necesidad de establecer indicadores que identifican a cada tipo de lector y cuya tipología sintetiza en:

Lector ingenuo:

- No tiene experiencia receptora.

- Presenta carencias a la hora de relacionar lecturas.

- Muestra un repertorio limitado.

\section{Lector competente:}

- Sabe que la lectura va más allá de la descodificación de signos.

- Sabe hacer una lectura y una interpretación personal de un modo coherente.

- Sabe relacionar textos con lecturas anteriores.

Pero, la formación de lectores reclama un cambio urgente en la metodología que se está aplicando. El desarrollo de la competencia literaria requiere un cambio en el proceso de enseñanza y aprendizaje de la literatura y este cambio pasa por conseguir que el alumnado disfrute de la lectura, la entienda, la haga suya y forme parte de su formación cultural. Para ello, la dinámica de las clases de literatura, las actividades que se realizan y los exámenes no pueden basarse en contenidos teóricos. El profesor/a hace de moderador y, en este papel, es imprescindible contagiarles pasión por los libros, por las diversas materias que se tienen que impartir. La figura del docente se 
presenta más crucial e innovadora que nunca como artífice imprescindible del cambio metodológico. Su papel, lejos de dar soluciones y respuestas, radica en ofrecer preguntas y dudas al alumnado para que sean ellos/as quienes se posicionen, busquen alternativas, desarrollen la creatividad y la independencia necesarias. Por eso, su papel va más allá del seguimiento y la evaluación del currículo.

Recordemos los objetivos fijados en el currículo de literatura para cuarto curso de Educación Secundaria Obligatoria para la Comunidad Autónoma de Canarias (Decreto 127/2007, de 24 de mayo):

1. Lectura de novelas y relatos desde el siglo XIX hasta la actualidad, incluyendo obras de la literatura canaria.

2. Lectura comentada y recitado de poemas contemporáneos, con atención a muestras de la literatura canaria, con especial atención a las aportaciones del simbolismo y las vanguardias al lenguaje poético, valorando la función de los elementos simbólicos y de los recursos retóricos y métricos en el poema.

3. Lectura comentada de relatos contemporáneos de diverso tipo, incluyendo obras de la literatura canaria, que ofrezcan distintas estructuras y voces narrativas.

4. Lectura comentada y dramatizada de breves piezas teatrales contemporáneas o de fragmentos de carácter diverso, con muestras de la literatura canaria, constatando algunas innovaciones en los temas y las formas.

5. Conocimiento de las características generales de los grandes periodos de la historia de la literatura desde el siglo XIX hasta la actualidad, con especial atención al modernismo, las vanguardias y la literatura de posguerra en Canarias.

6. Acercamiento a algunos autores relevantes de las literaturas hispánicas, incluyendo la canaria, y europea desde el siglo XIX hasta la actualidad.

7. Composición de textos de intención literaria y elaboración de trabajos y comentarios sobre lecturas.

8. Utilización autónoma de la biblioteca del centro, de las del entorno y de bibliotecas virtuales, así como participación en foros literarios.

9. Desarrollo de la autonomía lectora y aprecio por la literatura como fuente de placer y de conocimiento de otros mundos, tiempos y culturas.

De alguna forma, cada profesor debe personalizar, adaptar, reinventar la manera en que esos contenidos puedan transformarse en aprendizaje, y el docente es el primero en hacer uso de su creatividad, el primero en romper los moldes, dentro de su aula, de una enseñanza pasiva, tradicional y obsoleta. No es una tarea fácil. Se diseñan actividades que luego no funcionan como pensábamos y habrá que rediseñarlas. Además, el alumnado llega a Secundaria con la idea de tragar unos contenidos que 
debe escupir el día del examen para luego olvidarlos. En este contexto, está justificada la pregunta de los estudiantes: “ipara qué sirve esto?’. Quizá sea el momento de demostrarles su utilidad y lo conseguiremos cuando logremos que sean ellos quienes comprueben su utilidad, en la práctica, cuando comprueben que saben resolver, pensar, entender y opinar sobre cualquier texto, sobre cualquier discurso, y que les enseñará a saber estar de manera creativa y activa en la sociedad.

Nuestras propuestas didácticas se centran en actividades que requieren de la participación, de la creatividad y de la investigación del alumnado. Buscan trabajar la competencia en comunicación lingüística, competencia social y ciudadana, competencia cultural y artística, competencia para aprender a aprender y competencia en autonomía e iniciativa personal. El objetivo es que el aula se convierta en un lugar de reflexión, asimilación y aprendizaje, según el enfoque constructivista, que se centra en el alumno y en su proceso de investigación. Pero sin olvidar que, al inicio de cada clase, durante unos diez o quince minutos, se utilizará el modelo tradicional. El docente dará unas nociones básicas de conocimientos teóricos necesarios sobre los que ellos construirán su proceso de investigación y aprendizaje. Les ayudará a valorar la necesidad de partir de unos conocimientos teóricos para entender, en este caso, cómo y por qué surgen los diversos movimientos literarios y para comprobar su posible evolución y aplicación en el mundo actual.

Una vez acabada esta breve explicación teórica, se propondrá la actividad didáctica correspondiente y dividiremos la clase en tres tiempos:

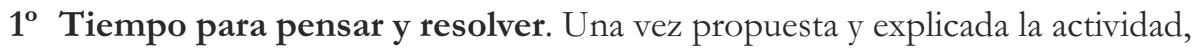
el alumnado deberá intentar hacerla él solo, sin ninguna intervención o aclaración del docente. Con ello, pretendemos que lean bien las instrucciones y piensen en cómo resolverla, aunque esté mal realizada, sin ningún tipo de ayuda. En muchas ocasiones, preguntan sin leer bien el enunciado, sin pararse a buscar una solución o, simplemente, están acostumbrados a que les resuelvan (hagan) las actividades sin antes comprobar que pueden hacerlo ellos. Y hemos comprobado que, al establecer este tiempo, aprenden a enfrentarse y a resolver ellos la actividad. Trabajo personal.

$2^{\circ}$ Tiempo de dudas. Se aclaran las posibles dudas. Trabajo en grupo.

$3^{\circ}$ Corrección y puesta en común de las actividades. Trabajo en grupo.

El tiempo destinado a cada apartado se medirá en función de las necesidades de cada curso en particular.

Vamos a explicar-trabajar el Romanticismo y el Realismo en cuarto curso de Educación Secundaria Obligatoria durante la primera evaluación. Una primera cuestión 
que hay que tener en cuenta es la de dosificar la cantidad de contenido histórico-teórico. Haremos una breve introducción contando cómo era la situación en el siglo XIX atendiendo a tres aspectos básicos: sociedad, política y cultura. Para conseguir que el alumno participe en esta parte, a priori tan aburrida para ellos, les sintetizaremos los aspectos fundamentales mediante el siguiente esquema:

\begin{tabular}{|c|c|c|}
\hline Romanticismo $1^{\circ} /$ XIX & Realismo $2^{\mathrm{a}}$ / XIX & Actualidad XXI \\
\hline $\begin{array}{l}\text { - Atraso y crisis económica } \\
\text { Sociedad: } \\
\text { - Burguesía: accede al } \\
\text { poder. } \\
\text { - Nobleza: decadencia. } \\
\text { - Clase trabajadora: } \\
\text { empieza a crecer. } \\
\text { Política: } \\
1^{\circ} \text { Napoleón invade España. } \\
2^{\circ} \text { Monarquía absoluta. } \\
3^{\circ} \text { Monarquía constitucional. } \\
\text { Cultura: } \\
\text { - Grave retraso cultural. } \\
\text { - Poca formación y acceso } \\
\text { a la educación de la } \\
\text { sociedad. } \\
\text { - Elevado analfabetismo. } \\
\text { Consecuencias: } \\
\text { - Inconformismo. } \\
\text { - Espíritu revolucionario. } \\
\text { - Necesidad de cambio. } \\
\text { - Visión idealista de la reali- } \\
\text { dad. }\end{array}$ & $\begin{array}{l}\text { - Revolución industrial } \\
\text { Sociedad: } \\
\text { - Burguesía: desarrollo. } \\
\text { - Nobleza: decae. } \\
\text { - Clase trabajadora: lucha } \\
\text { por sus derechos. } \\
\text { Política: } \\
1^{\circ} \text { Cambios de gobierno. } \\
2^{\circ} \text { Restauración borbóni- } \\
\text { ca. Estabilidad política. } \\
\text { Cultura: } \\
\text { - Avances tecnológicos. } \\
\text { - Positivismo: obser- } \\
\text { vación y comprobación } \\
\text { empírica. } \\
\text { - Evolucionismo. } \\
\text { Consecuencias: } \\
\text { - Oposición al romanti- } \\
\text { cismo. } \\
\text { - Observación de la rea- } \\
\text { lidad } \\
\text { - Visión realista: denuncia } \\
\text { social. }\end{array}$ & Consecuencias: \\
\hline
\end{tabular}

Elaboración propia

Uno de los objetivos que perseguimos con esta introducción, además de que comprueben los cambios o no que han tenido lugar a lo largo de los siglos, es que sean conscientes de los factores que hacen posible la aparición de un movimiento literario, en este caso el Romanticismo y el Realismo. 


\section{$1^{a}$ Propuesta didáctica}

\section{Atrévete a pensar}

\section{Completa la columna del siglo XXI}

En el siguiente esquema se sintetiza el contenido teórico que explica las principales características del Romanticismo y del Realismo y cuáles fueron las circunstancias que propiciaron su aparición. Empezamos por unas nociones básicas sobre el Neoclasicismo para demostrar que el Romanticismo surge por oposición al racionalismo desarrollado en el siglo XVIII. Del mismos modo que el Realismo surge como contraposición al espíritu romántico. Resaltamos las particularidades de cada movimiento a partir de sus diferencias con el movimiento anterior. Se agota la fórmula aplicada durante un siglo y la nueva fórmula es contraria a la anterior. Como si la historia de la literatura fuera cíclica, o como una montaña rusa, que sube y baja, y se modifica en función de la preponderancia de las dos pulsiones que determinan al ser humano: la razón y los sentimientos, y que se van alternando en cada época. Todo vuelve, con pequeñas modificaciones, para luego irse y volver a aparecer. Aunque hoy disfrutemos de los adelantos tecnológicos: internet, móvil, ordenador, etc., tal vez, seguimos teniendo la misma esencia, las mismas pulsiones humanas que las personas de los siglos anteriores.

\begin{tabular}{|c|c|c|}
\hline Neoclasicismo (XVIII) & Romanticismo $\left(1^{\mathrm{a}} / \mathrm{XIX}\right)$ & Realismo ( $\left.2^{\mathrm{a}} / \mathrm{XIX}\right)$ \\
\hline - Razón: ciencia es progreso. & - Sentimientos: pasión-amor. & $\begin{array}{l}\text { - Razón: progreso } \\
\text { científico. }\end{array}$ \\
\hline $\begin{array}{l}\text { - Optimismo: cultura = liber- } \\
\text { tad. }\end{array}$ & $\begin{array}{l}\text { - Pesimismo: angustia vital. } \\
\text { - Concepción del mundo: }\end{array}$ & $\begin{array}{l}\text { - Humanismo-Realidad: } \\
\text { centro }\end{array}$ \\
\hline $\begin{array}{l}\text { - Concepción del mundo: } \\
\text { necesidad del conocimiento } \\
\text { didáctico y la educación } \\
\text { social. }\end{array}$ & $\begin{array}{l}\text { exceso de normas- falta de } \\
\text { libertad. }\end{array}$ & $\begin{array}{l}\text { - Concepción del mundo: } \\
\text { Positivismo: observación } \\
\text { y experimentación. }\end{array}$ \\
\hline $\begin{array}{l}\text { - Objetividad: sociedad. } \\
\text { - Es importante educar al } \\
\text { pueblo. }\end{array}$ & $\begin{array}{l}\text { - Subjetividad: individuo. } \\
\text { - Libertad frente a las normas. } \\
\text { Espíritu revolucionario. }\end{array}$ & $\begin{array}{l}\text { - Objetividad: sociedad. } \\
\text { - Observación y descrip- } \\
\text { ción detallada de la reali- } \\
\text { dad. }\end{array}$ \\
\hline
\end{tabular}




\section{Blanca Hernández Quintana}

Enseñanza y aprendizaje de la Literatura en Secundaria: Romanticismo y Realismo

\begin{tabular}{|c|c|c|}
\hline Neoclasicismo (XVIII) & Romanticismo (1 / XIX) & Realismo ( $\left.2^{\mathrm{a}} / \mathrm{XIX}\right)$ \\
\hline $\begin{array}{l}\text { - Estilo: sencillo -armonía y } \\
\text { equilibro según los cánones } \\
\text { clásicos. } \\
\text { - Autores principales: } \\
\text { - Samaniego: Fábulas: } \\
\text { moraleja. } \\
\text { - Teatro: Moratín: didáctico- } \\
\text { moralizante. El sí de las } \\
\text { niñas. } \\
\text { - Color: ¿? }\end{array}$ & $\begin{array}{l}\text { - Literatura: poesía } \\
\text { - Temas: amor y existencia. } \\
\text { - Amor trágico, platónico, no } \\
\text { correspondido. } \\
\text { - Autor subjetivo: expresa } \\
\text { sus sentimientos. } \\
\text { - Existencia: fuente de } \\
\text { agonía y frustración. } \\
\text { - Estilo: sonoro y expresivo. } \\
\text { Libertad de las formas } \\
\text { métricas. } \\
\text { - Autores principales: } \\
\text { - Bécquer, Espronceda y } \\
\text { Rosalía de Castro. } \\
\text { - Color: ¿? }\end{array}$ & $\begin{array}{l}\text { - Literatura: prosa } \\
\text { - Temas: reproducir la } \\
\text { realidad, denuncia y } \\
\text { crítica social. } \\
\text { - Análisis riguroso de la } \\
\text { realidad y de lo } \\
\text { psicológico: retrato } \\
\text { de lo observado. } \\
\text { - Autor objetivo y omnis- } \\
\text { ciente: todo lo sabe. } \\
\text { - Estilo: sencillo, sobrio, } \\
\text { diálogos y descripciones. } \\
\\
\text { - Autores principales: } \\
\text { - Galdós, Valera, Clarín } \\
\text { y Emilia Pardo Bazán. } \\
\text { - Color: ¿? }\end{array}$ \\
\hline
\end{tabular}

Elaboración propia

\section{$2^{a}$ Propuesta didáctica}

\section{Coloreando la literatura}

Elige un color que represente el espíritu de cada movimiento literario

\section{$3^{\text {a }}$ Propuesta didáctica}

\section{La literatura en el cine}

Podemos decir que en la literatura los temas sobre los que siempre se han escrito son el amor (correspondido, no correspondido, idealizado, etc.), la existencia (muerte, paso del tiempo, sentido de la vida, etc.) y la crítica social (desigualdad, injusticias, denuncias, etc.). Cada movimiento literario, cada autor, lo ha abordado según la situación de la época que le ha tocado vivir, pero, de alguna manera, estos temas siempre han estado presentes en todas las manifestaciones artísticas, como en el caso del cine. 
Piensa en películas que hayas visto en el cine y elije dos: una que creas que tenga un corte romántico y otra, un corte realista. Resume el argumento de cada película en cinco renglones y explica las características románticas y realistas que has observado en dichas películas. (Algunos alumnos eligieron como películas de corte romántico "Crepúsculo" o "Tres metros sobre el cielo", y de corte realista "Criadas y señoras" o "El niño del pijama de rayas").

\section{$4^{\mathrm{a}}$ Propuesta didáctica}

\section{Dibujando la literatura}

Elabora un dibujo estableciendo un símil en el que se ponga de manifiesto la evolución de un mismo tema tratado de diferente forma. Vale cualquier tema. (Un alumno eligió como tema un pantalón vaquero y dibujó las diversas maneras en que se ha ido llevando desde su existencia: ajustado, suelto, elástico, de pata de campana, etc.).

Vivimos en una época dominada por lo visual. La imagen ha ido tomando un mayor protagonismo y la publicidad es el principal ejemplo. Proponemos con esta actividad educar la mirada porque debajo de cada imagen hay un código que descifrar, una lectura oculta. Creemos que es primordial inculcar al alumnado la importancia de aprender a descodificar, a analizar, a desmontar la imagen para averiguar qué les quiere transmitir, qué sentimientos les produce y qué opinión les merece.

\section{$5^{\circ}$ Propuesta didáctica}

\section{Los cuadros hablan}

Se les enseñan dos cuadros:

$1^{\circ}$ El cuadro de Alphonse Marie Mucha titulado "Las estaciones: verano": muestra a una mujer joven, apoyada en la rama de un árbol, con un vestido muy sensual. Sus pies desnudos acarician el agua. Está rodeada de naturaleza. Hay mucho colorido.

$2^{\circ}$ El cuadro de Murillo titulado "Niños comiendo fruta": dos niños con la ropa muy desgastada comen fruta sentados en la calle. No tienen zapatos. Los colores son apagados. Domina el tono grisáceo. 
Se les pide que las observen detenidamente y luego se les propone las siguientes actividades:

- Ponle un título a cada cuadro.

- Indica cuál de estos cuadros representa mejor las características románticas y cuál las características realistas.

- Explica qué aspectos del movimiento literario elegido observas en cada cuadro.

- ¿Cuál te gusta más? ¿Por qué?

\section{$6^{\circ}$ Propuesta didáctica}

\section{Interpretando la literatura}

Textos para analizar:

- Identifica a qué movimiento literario pertenece cada texto y justifica tu respuesta.

- ¿Qué idea de la mujer se representa en cada texto?

- ¿Crees que ha cambiado la visión y la realidad de la mujer en la actualidad? ¿Por qué?

\section{Техто A}

A solas en su alcoba, algunas noches en que la tristeza la atormentaba, Ana volvía a escribir versos, pero los rasgaba en seguida y arrojaba el papel por el balcón para que sus tías no tropezasen con el cuerpo del delito. La persecución en esta materia llegó a tal extremo, tales disgustos le causó su afán de expresar por escrito sus ideas y sus penas, que tuvo que renunciar en absoluto a la pluma; se juró a sí misma no ser la «literata», aquel ente híbrido y abominable de que se hablaba en Vetusta como de los monstruos asquerosos y horribles. Las amiguitas, que habían sabido algo, y nunca tenían qué censurar en Ana, aprovecharon este flaco para ponerla en ridículo delante de los hombres, y a veces lo consiguieron. 


\section{Texto B}

Mientras se sienta que se ríe el alma,

sin que los labios rían;

mientras se llore, sin que el llanto acuda

a nublar la pupila;

mientras el corazón y la cabeza

batallando prosigan,

mientras haya esperanzas y recuerdos,

¡habrá poesía!

Mientras haya unos ojos que reflejen

los ojos que los miran,

mientras responda el labio suspirando

al labio que suspira,

mientras sentirse puedan en un beso

dos almas confundidas,

mientras exista una mujer hermosa,

¡habrá poesía!

\section{$7^{a}$ Propuesta didáctica}

\section{Tras-tocando los textos}

Reescribe los textos anteriores transformando el texto romántico en uno realista y el realista en uno romántico. Haz todos los cambios que creas oportunos.

\section{$8^{\mathrm{a}}$ Propuesta didáctica}

\section{Saboreando literatura}

Elabora un menú de corte romántico y otro de corte realista atendiendo a las características que definen dichos movimientos. Propuesta de los alumnos: 
Enseñanza y aprendizaje de la Literatura en Secundaria: Romanticismo y Realismo

\begin{tabular}{|c|c|}
\hline Menú romántico & Menú realista \\
\hline $\begin{array}{l}\text { - Bebida: Champán } \\
\text { - Entrantes: aguacate con gambas y salsa rosa. } \\
\text { - Primer plato: sopa de marisco. } \\
\text { - Segundo plato: bacalao con pimientos de piquillo y } \\
\text { especias. } \\
\text { - Postre: mousse de chocolate con sirope de canela. } \\
\text { - Licor de arándanos. }\end{array}$ & $\begin{array}{l}\text { - Bebida: agua } \\
\text { - Entrantes: pan y queso. } \\
\text { - Primer plato: potaje de lentejas. } \\
\text { - Segundo plato: sancocho canario } \\
\text { - Postre: naranja y plátano. } \\
\text { - Un cortado. }\end{array}$ \\
\hline
\end{tabular}

Elaboración propia

\section{$9^{a}$ Propuesta didáctica}

\section{Hablando de literatura}

Tema para debatir en clase:

Si tuvieras que elegir entre el Romanticismo o el Realismo para definir a nuestra sociedad actual ¿por cuál optarías? Justifica tu respuesta.

(Respuesta abierta. Mientras justifiquen su elección las dos opciones son válidas, o la mezcla de las dos).

\section{$10^{a}$ Propuesta didáctica}

\section{Soñando con literatura}

Taller creativo:

"Me gusta-no me gusta": escribe un texto subjetivo sobre las cosas que te gustan y las que no.

"Quiero denunciar": escribe un texto objetivo sobre alguna injusticia social que quieras denunciar. 


\section{CONCLUSIÓN}

Las actividades propuestas pretenden conseguir que el alumnado conciba la literatura como algo cercano, placentero y fácil de entender y asimilar. Intenta, además, que comprendan que, aunque estamos hablando de dos movimientos literarios desarrollados en el siglo XIX, siguen muy presentes en la actualidad.

Asimismo, busca que comprueben que el Romanticismo y el Realismo no han desaparecido, y no son dos bloques teóricos de autores y características que memorizar, sino todo lo contrario. No son un recuerdo. Están vivos, sus huellas siguen presentes en la actualidad, con pequeñas modificaciones y actualizaciones, en la moda, el cine, las imágenes, la forma de vestir, la gastronomía, la manera en que cada persona percibe el mundo, etc.

Intentamos que se acerquen a los textos sin miedo, sin miedo a no comprenderlos y que, a su vez, sean capaces de jugar con ellos, de desmontarlos, de encontrarles una significación y una aplicación en la vida real.

Quizá, estos dos movimientos sinteticen, sobremanera, las dos perspectivas desde las que posicionarse en el mundo: individualismo/yo frente a sociedad/ nosotros, y les ayude a conocerse mejor a sí mismos.

\section{Bibliografía}

Ballester, J. (1998). "Las teorías literarias y su aplicación didáctica" en Mendoza, A. (coord.): Conceptos clave en didáctica de la lengua y la literatura, Barcelona: Universidad de Barcelona.

Bordons, G. y Díaz-Plaja, A. (2006). "Las aportaciones de la teoría de la literatura a la enseñanza" en Bordons, G. y Díaz-Plaja, A. (coords.): Enseñar literatura en secundaria, Barcelona: Graó.

Castellá, J. (2007). Entender(se) en clase, Barcelona: Graó.

Colomer, T. (1996). Enseñar a leer, enseñar a comprender, Madrid: Celeste.

Gómez, F. (2002). Didáctica de la poesía en la Educación Secundaria, Madrid: Ministerio de Educación Cultura y Deporte.

Mendoza, A. (2004). La educación literaria: bases para la formación de la competencia lecto-literaria, Málaga: Aljibe.

Millás, JJ. (2008). Articuentos, Madrid: Alba.

Silió, E. (2013). "La buena escuela no asfixia la creatividad", El País digital, 8/04/ 2013.

Silió, E. y García De Blas, E. (2014) “Suspenso en la vida real”, El País digital, 01/04/2014.

blanca.hernandez@ulpgc.es 